\title{
Community-level analyses of long-term changes in rocky littoral fauna from South Africa
}

\author{
A. H. Dye* \\ Department oi Zoology, University of Transkei, Umtata, Eastern Cape, South Africa 5117
}

\begin{abstract}
Changes in the structure of benthic invertebrate communities in undisturbed and experimentally cleared quadrats on 3 rocky shores on the east coast of South Africa were monitored quarterly for $14 \mathrm{yr}$ from 1982. There were no clear long-term trends in species diversity in either undisturbed or experimentally cleared areas. Diversity decreased and became more variable following disturbance and remained so throughout the study. Fourier analyses revealed significant annual cycles in diversity in undisturbed areas at all sites, while only half of the cleared areas exhibited significant annual cycles. Non-metric multidimensional scaling ordinations, based on Bray-Curtis similarity matrices, were used to represent traces of the 'state' of the community through time at each site. Undisturbed areas typically exhibited 2 or more apparently stable states, persisting for periods exceeding the turnover time of the dominant populations, with brief periods of instability between them. Fluctuations in the abundance of barnacles and periwinkles accounted for most of the differences between these states. The lower balanoid zone community tended to oscillate between states more frequently than that in the upper balanoid zone. Correlations between traces from different sites tended to be stronger for high shore communities than for those lower on the shore. Disturbed communities either converged to a stable state, persisting for more than $10 \mathrm{yr}$, or remained unstable throughout the study. Similarities in longterm variability between sites suggest the influence of large-scale factors affecting the supply and survival of larvae.
\end{abstract}

KEY WORDS: Rocky littoral · Community · Long-term variability · Disturbance $\cdot$ Stability

\section{INTRODUCTION}

A number of studies have pointed to the importance of long-term data sets in understanding the variability of natural marine systems (Southward 1967, 1991, Lewis 1976, Underwood 1984, Paine 1986, Butler \& Chesson 1990, Barry et al. 1995, Southward et al. 1995). Such data not only provide a background against which to evaluate short-term experimental studies, which have been important in elucidating species interactions such as grazing, predation and competition (Dungan 1986, Menge et al. 1986, Petraitis 1990, Dye \& White 1991, Dye 1992, 1995), but they can also provide insights into important long-term processes which could not be detected by, or could confound, short-term studies (Garrity \& Levings 1981, Connell 1985, Fairweather 1988, Barry et al. 1995).

•E-mail: dye@getafix.utr.ac.za
These include the effects of variations in recruitment and mortality (Kendall et al. 1985), variations in primary production (Frid et al. 1996), climate change (Barry et al. 1995), anthropogenic disturbances (Southward 1967), and stochastic events (Hawkins \& Hartnoll 1983, Foster \& Shiel 1993, Francis \& Evans 1993).

Despite their potential importance (Southward 1995), there have been relatively few long-term studies of rocky intertidal systems (Barnes 1956, Southward 1967, Luckens 1976, Kendall et al. 1982, 1985, Caffey 1985, Judge et al. 1988). Furthermore these studies have generally focussed on the population level and the analyses are essentially univariate in nature (Hawkins \& Hartnoll 1983, Kendall et al. 1985. Southward 1991, Barry et al. 1995, Southward et al. 1995, Frid et al. 1996). Such an approach can tell us much about population dynamics (Kendall et al. 1985), and the effects of stochastic events on individual species (Dye 1990), and on the more theoretical aspects of 
variability, such as temporal redshifts (Steele 1985, Pimm \& Redfearn 1988) and non-linear phenomena (Turchin \& Taylor 1992, Ellner \& Turchin 1995). However, higher level approaches, involving communitylevel attributes and multivariate techniques, are better suited to illustrating how communities vary over time (Lively et al. 1993), or respond to disturbance (Warwick 1986, Warwick \& Clarke 1991, 1993, 1995, Lasiak \& Field 1995).

This paper is the second report on a long-term study of rocky shores on the east coast of South Africa, and presents community-level analyses of 14 yr data on the abundance of experimentally disturbed and undisturbed mid-littoral populations. Given the highly variable nature of recruitment processes and their importance in structuring intertidal communities (Southward 1967, Kendall et al. 1982), the initial hypothesis was that temporal and spatial fluctuations in the abundance of species would be highly stochastic and therefore independent of each other, and possibly also of the scale on which they were measured. The objective was therefore to establish the nature and extent of natural fluctuations in colonization and recruitment in midand upper intertidal communities at large spatial and temporal scales, and to contrast this with the effects of a clearly defined pulse disturbance created by experimental clearing, both to test this hypothesis (Dye in press), and as a background to the interpretation of experimental data on community interactions and human impacts. The underlying hypothesis examined in the present analysis is an extension of the first and holds that community-level attributes, such as species diversity and community structure, will exhibit stochastic temporal and spatial variability, again independent of each other and of the scale on which they are measured.

\section{METHODS}

Benthic populations in the mid- and upper-littoral were monitored from November 1982 at 2 sites, Mazeppa Bay $\left(28^{\circ} 06^{\prime} \mathrm{E}, 32^{\circ} 41^{\prime} \mathrm{S}\right)$ and Dwesa $\left(28^{\circ} 50^{\prime} \mathrm{E}, 32^{\circ} 18^{\prime} \mathrm{S}\right)$, and from November 1983 at a third site, Mkambati $\left(30^{\circ} \mathrm{E}, 31^{\circ} 16^{\prime} \mathrm{S}\right)$ on the south-east coast of South Africa. This is a summer rainfall region which experiences an annual precipitation of $1100 \mathrm{~mm}$. Air temperature ranges from 13 to $35^{\circ} \mathrm{C}$ with a mean of $20^{\circ} \mathrm{C}$ and, although the prevailing winds are from the south-west, frequent easterlies also occur. Sea temperature varies from $10^{\circ} \mathrm{C}$, during occasional upwelling, to $24^{\circ} \mathrm{C}$, with a mean of $18^{\circ} \mathrm{C}$. Tides are semi-diurnal with an amplitude of approximately $2 \mathrm{~m}$, and all sites experience continuous moderate to heavy wave action, mainly from the south-west.
Benthic communities in the upper balanoid zones at Dwesa and Mkambati comprise 12 and 10 species respectively and are characterized by the rock oyster Saccostrea cucullata and the barnacle Chthamalus dentatus. Other species are the limpets Cellana capensis, Patella granularis, Fissurella natalensis and Patelloida profunda, the periwinkles Nodilittorina africana and Oxystele tabularis, the predatory whelk Burnupena lagenaria and the barnacles Tetraclita serrata and Octomeris angulosus. Extending below this zone to about $30 \mathrm{~cm}$ above the low spring tide level is the lower balanoid zone, characterized by Tetraclita serrata and Octomeris angulosus. The same species occur as in the upper zone with the addition of the brown mussel Perna perna and the limpet Siphonaria concinna. While these species are also present at Mazeppa, the rock oyster is usually absent as this is the extreme southern limit of its distribution in Africa. The lowshore zone extends down to the spring low-water level and in marine reserves supports inter alia large numbers of $P$. perna, various patellid limpets and numerous species of algae. A more comprehensive description of these shores is given in Dye (1988) and Dye (in press).

The analyses are based on abundance data, obtained at quarterly intervals, from 16 monochrome photographs of $0.25 \mathrm{~m}^{2}$ quadrats located within an approximately $5 \times 20 \mathrm{~m}$ area parallel to the sea in the upper and lower balanoid zones at Dwesa and Mkambati. The quadrats, initially chosen at random, were marked and revisited on each subsequent sampling occasion. Owing to the steep profile of the shore at Mazeppa, only the lower balanoid zone was monitored at this site. These data are compared with that from adjacent quadrats which had been subjected to a clearly defined pulse disturbance, created by removing all macro-organisms from successive sets of quadrats seasonally during the first year of the study (Dye in press).

The Shannon-Wiener index of diversity $H^{\prime}$ was used to describe changes in the communities over time. In addition non-metric multidimensional scaling ordinations (MDS), based on Bray-Curtis similarity matrices of root-transformed abundance data, were used to create 2-dimensional representations of the temporal state of the communities. These analyses were performed using the PRIMER suite of programmes developed by the Plymouth Marine Laboratory (Warwick \& Clarke 1991, Clarke 1993). The clusters thus produced consisted of groups of sampling dates representing a particular 'state' of the community defined by the relative numerical abundance of the component species. The species contributing most to the mean difference between different community 'states' at each site were identified using the Similarity Percentages (SIMPER) routine of PRIMER. While the ordinations may indicate 
that communities occupy distinct states over time, they do not provide a clear picture of how they change from one state to another. One way to represent these changes is to join the points in each ordination to produce a trace of the path of the community through time. However, with a relatively large number of points as in the present case, this would result in a very jumbled picture with no more clarity than the original ordination. To overcome this the trace produced by joining the data points was 'stretched out' and plotted against time to produce a series of 'timelines' for the clusters at each site, thus providing a clear representation of temporal changes in state.

Fourier analyses were performed on the detrended time series. First order autocorrelations, present in virtually all cases, could usually be corrected by lag-1 differencing (Chatfield 1989). The resulting periodograms were tested against an exponential distribution (white noise) using the Bartlett-Kolmogorov-Smirnov $D$ statistic (Diggle 1990).

\section{RESULTS}

Fig. 1 shows time series of species diversity in undisturbed and experimentally cleared areas in the lower balanoid zone at Mazeppa, and in the upper and lower balanoid zones at Dwesa and Mkambati. Although no overall trends were evident in undisturbed communities, some time series, such as those from Dwesa and the upper balanoid zone at Mkambati, showed a decline in diversity between 1982 and approximately 1989 , followed by a sharp increase between 1989 and 1991 and subsequent decline. This discontinuity separates the time series into 2 distinct parts which differ in both mean diversity and variability (Table 1). Diversity was generally lower and tended to be more variable in undisturbed areas in the period prior to 1989 than after this date. Mean diversity increased in a northerly direction, from $0.60 \pm 0.22 \mathrm{SD}$ at Mazeppa to $0.73 \pm 0.37$ at Dwesa and $1.09 \pm 0.20$ at Mkambati, all sites being significantly different ( $t$-test; $\mathrm{p} \leq$ 0.001). There were no significant within or between site correlations in diversity in undisturbed areas. Fourier analysis revealed significant annual cycles in diversity in undisturbed areas at all sites (Table 2) and biennial cycles at some sites.

With the exception of summer clearings at Mazeppa, species diversity in experimentally disturbed areas was generally lower and more variable than in undisturbed areas (Table 1) and remained so throughout the study. There were significant differences in mean diversity between the early and later parts of the time series in all cleared areas at Dwesa, in areas cleared in summer at Mazeppa and in summer and autumn at Mkambati. Coefficients of variability in all cleared areas were generally lower after 1990 than earlier in the study. The sig-
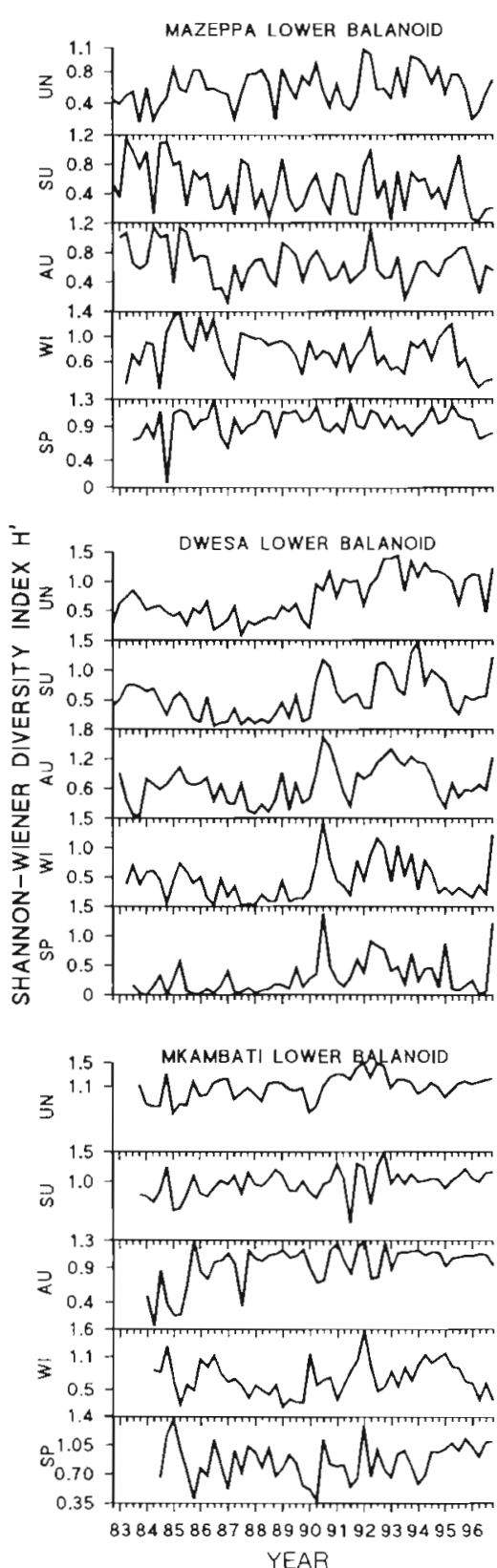

Fig. 1 Shannon-Wiener diversity time series for undisturbed and seasonally cleared areas at Mazeppa, Dwesa and Mkambati. UN: undisturbed; SU: summer; AU: autumn; WI: winter; SP: spring
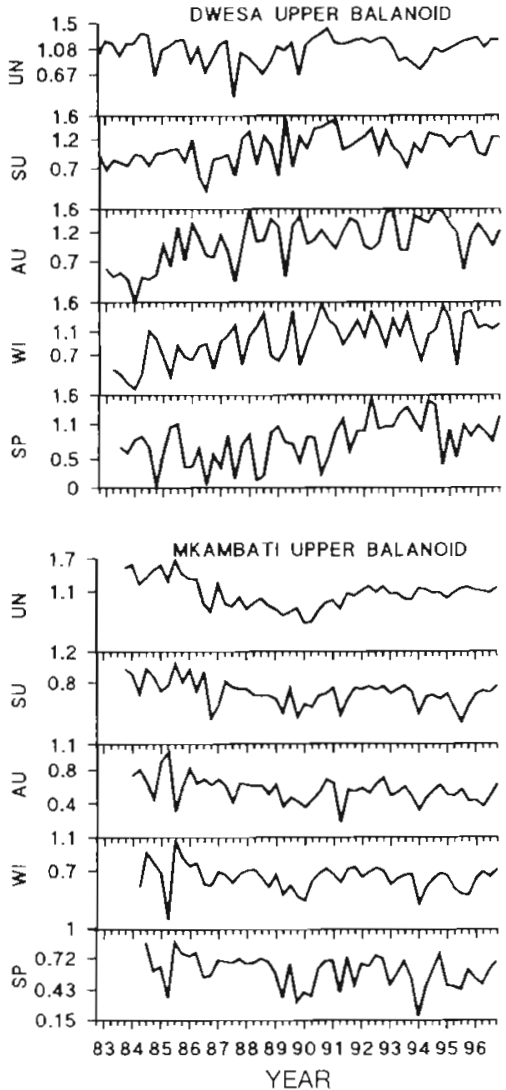
Table 1. Comparisons of mean diversity for sites at Mazeppa, Dwesa and Mkambati for the periods 1982 to 1989 and 1990 to 1996. Also given are the overall mean diversities and coefficients of variation ( $C V, \%)$. UBZ: Upper Balanoid Zone; LBZ: Lower Balanoid Zone; UN: undisturbed; SU: summer clearing; AU: autumn clearing; WI: winter clearing; SP: spring clearing. ns = not significant

\begin{tabular}{|c|c|c|c|c|c|c|c|c|}
\hline \multirow[t]{2}{*}{ Site } & \multicolumn{2}{|c|}{$1982-1989$} & \multicolumn{2}{|c|}{$1990-1996$} & \multirow[t]{2}{*}{$t$} & \multirow[t]{2}{*}{$\mathrm{p}$} & \multicolumn{2}{|c|}{ Overall } \\
\hline & $\bar{x}$ & CV & $\bar{x}$ & $\mathrm{CV}$ & & & $\tilde{X}$ & $\mathrm{CV}$ \\
\hline Mazeppa LBZ UN & 0.55 & 36.4 & 0.65 & 35.4 & & ns & 0.60 & 36.1 \\
\hline SU & 0.57 & 59.6 & 0.42 & 64.3 & 2.14 & 0.036 & 0.50 & 64.0 \\
\hline $\mathrm{AU}$ & 0.68 & 42.6 & 0.59 & 33.9 & & ns & 0.64 & 40.6 \\
\hline WI & 0,86 & 36.0 & 0.67 & 40.3 & & ns & 0.76 & 40.8 \\
\hline $\mathrm{SP}$ & 0.93 & 26.9 & 0.96 & 14.6 & & ns & 0.94 & 21.3 \\
\hline Dwesa UBZ UN & 1.02 & 22.5 & 1.13 & 15.9 & 2.06 & 0.04 & 1.07 & 19.6 \\
\hline SU & 0.90 & 28.9 & 1.18 & 16.1 & 4.93 & 0.001 & 1.04 & 26.0 \\
\hline $\mathrm{AU}$ & 0.83 & 48.2 & 1.21 & 21.5 & 3.86 & 0.003 & 1.02 & 38.2 \\
\hline WI & 0.78 & 44.9 & 1.13 & 24.8 & 4.81 & 0.001 & 0.96 & 38.5 \\
\hline $\mathrm{SP}$ & 0.62 & 51.6 & 0.97 & 34.0 & 3.91 & 0.001 & 0.81 & 45.7 \\
\hline Dwesa LBZ UN & 0.46 & 39.0 & 0.99 & 31.3 & 7.16 & 0.001 & 0.73 & 50.7 \\
\hline $\mathrm{SU}$ & 0.37 & 62.0 & 0.73 & 47.9 & 4.08 & 0.001 & 0.55 & 63.6 \\
\hline $\mathrm{AU}$ & 0.52 & 57.7 & 0.86 & 45.3 & 3.12 & 0.003 & 0.70 & 54.3 \\
\hline Wl & 0.31 & 74.2 & 0.57 & 64.9 & 2.44 & 0.017 & 0.45 & 48.5 \\
\hline SP & 0.15 & 100.0 & 0.44 & 79.5 & 3.82 & 0.001 & 0.30 & 100.0 \\
\hline Mkambati UBZ UN & 1.05 & 32.4 & 1.0 & 18.0 & & ns & 1.04 & 24.5 \\
\hline SU & 0.70 & 27.1 & 0.51 & 24.0 & 2.58 & 0.013 & 0.57 & 28.1 \\
\hline$\Delta I$ & 0.60 & 26.7 & 0.61 & 19.7 & 2.68 & 0.009 & 0.60 & 25.8 \\
\hline WI & 0.63 & 30.2 & 0.60 & 20.0 & & ns & 0.62 & 25.8 \\
\hline $\mathrm{SP}$ & 0.62 & 24.2 & 0.56 & 26.8 & & ns & 0.60 & 25.0 \\
\hline Mkambati LBZ UN & 0.98 & 19.4 & 1.16 & 16.3 & 3.06 & 0.003 & 1.09 & 18.3 \\
\hline SU & 0.89 & 20.2 & 1.02 & 22.5 & & ns & 0.97 & 22.7 \\
\hline $\mathrm{AU}$ & 0.82 & 41.5 & 1.02 & 16.5 & 3.26 & 0.002 & 0.94 & 30.8 \\
\hline WI & 0.64 & 48.4 & 0.76 & 40.8 & & ns & 0.71 & 43.7 \\
\hline $\mathrm{SP}$ & 0.82 & 29.3 & 0.85 & 25.9 & & ns & 0.85 & 25.9 \\
\hline
\end{tabular}

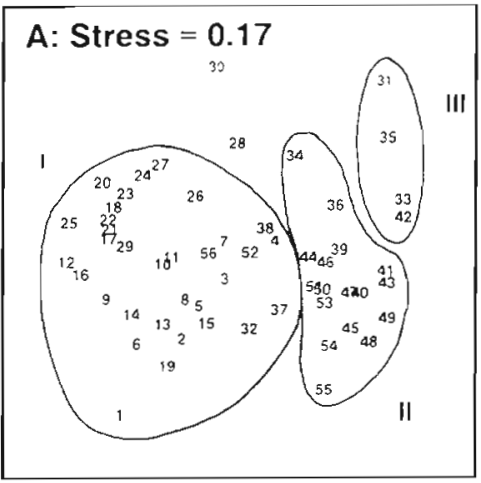

\section{B: Stress $=0.14$}
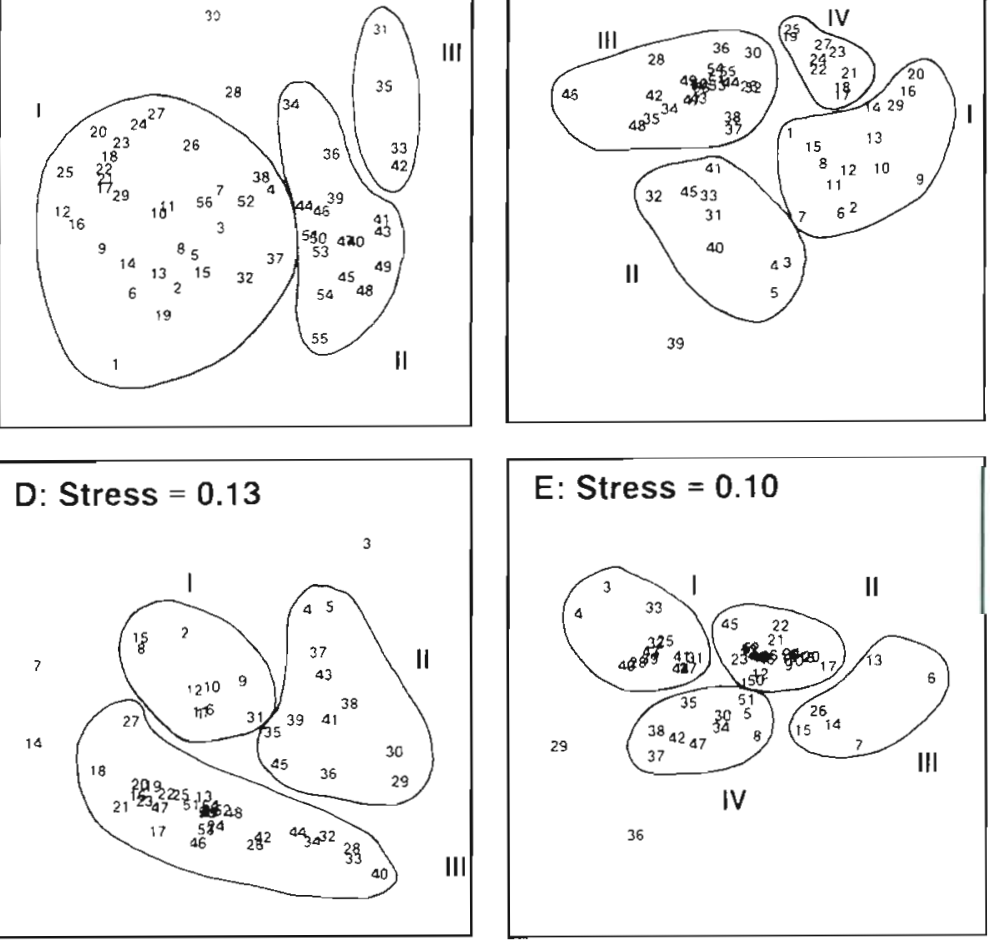

nificant annual cycles in diversity characteristic of undisturbed areas were less obvious in cleared areas, where only half of the treatments exhibited significant cycles (Table 2). Only 2 of these also exhibited biennial cycles.

Fig. 2 shows an example of a nonmetric MDS for cleared and undisturbed areas in the lower balanoid zone at Dwesa. For the sake of brevity and to avoid repetition, the other MDS plots are omitted as these data are presented and discussed below as timelines. Relatively low stress values $(\bar{x}=$ 0.15 ) indicate a good representation of the ordinations in 2 dimensions (Clarke 1993). The numbers in each ordination represent sequential samples taken at 3-monthly intervals. Number ' 1 ' is November 1982 (November 1983 at Mkambati). Clusters are numbered clockwise starting with the cluster containing the first observation. Should this observation be an outlier, numbering starts with the cluster containing the next observation and so on. The clusters represent the 'state' of a community, derived from the relative numerical abundance of

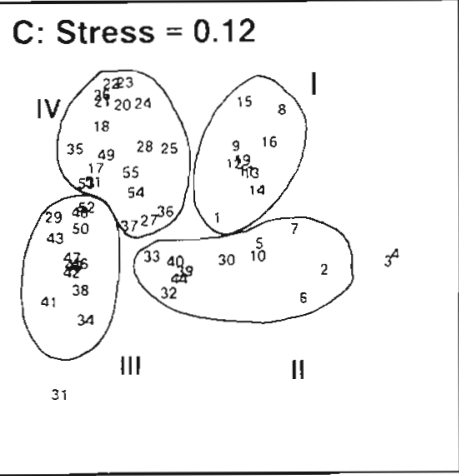

Fig. 2. Non-metric multidimensional scaling ordinations (MDS) ordinations for undisturbed and seasonally cleared areas in the lower balanoid zone at Dwesa. (A) Undisturbed; (B) summer; (C) autumn; (D) winter; (E) spring 
Table 2. Results of periodogram analyses of species diversity time series from Mazeppa, Dwesa and Mkambati. UN: undisturbed; SU: summer clearing; AU: autumn clearing; WI: winter clearing; SP: spring clearing. Cycles: 1 = annual, 2 = biennial. $D_{\text {rnax }}$ : Bartlett-Kolmogorov-Smirnov $D$ statistic; ns: not significant

\begin{tabular}{|c|c|c|c|}
\hline Site & Cycle & $D_{\max }$ & $\mathrm{p}$ \\
\hline $\begin{array}{l}\text { Mazeppa lower balanoid UN } \\
\text { SU }\end{array}$ & 1,2 & 0.219 & $\begin{array}{r}0.02 \\
\text { ns }\end{array}$ \\
\hline $\mathrm{AU}$ & 1 & 0.237 & 0.005 \\
\hline WI & 1 & 0.278 & 0.001 \\
\hline SP & & & ns \\
\hline $\begin{array}{l}\text { Dwesa upper balanoid UN } \\
\text { SU }\end{array}$ & 1,2 & 0.209 & $\begin{array}{c}0.05 \\
\text { ns }\end{array}$ \\
\hline $\mathrm{AU}$ & 1,2 & 0.250 & 0.002 \\
\hline WI & & & ns \\
\hline $\mathrm{SP}$ & & & ns \\
\hline Dwesa lower balanoid UN & 1,2 & 0.275 & 0.001 \\
\hline SU & 1 & 0.209 & 0.05 \\
\hline $\mathrm{AU}$ & & & ns \\
\hline WI & & & ns \\
\hline $\mathrm{SP}$ & 1,2 & 0.190 & 0.05 \\
\hline $\begin{array}{l}\text { Mkambati upper balanoid UN } \\
\text { SU }\end{array}$ & 1 & 0.311 & $\begin{array}{c}0.001 \\
\text { ns }\end{array}$ \\
\hline $\mathrm{AU}$ & & & ns \\
\hline WI & & & ns \\
\hline $\mathrm{SP}$ & & & ns \\
\hline Mkambati lower balanoid UN & 1 & 0.229 & 0.02 \\
\hline SU & 1 & 0.311 & 0.001 \\
\hline $\mathrm{AU}$ & 1 & 0.312 & 0.001 \\
\hline WI & 1.2 & 0.259 & 0.002 \\
\hline $\mathrm{SP}$ & 1 & 0.224 & 0.02 \\
\hline
\end{tabular}

its component species at various points in time, and are based on groups differing by at least $25 \%$ in the original similarity dendrograms.

With the exception of a small number of outlying points, undisturbed communities generally occupied between 2 and 4 distinct states, with the number increasing in a northerly direction. An important feature of the clusters at all sites is the fact that they consist of sequences of samples which collectively form non-sequential groupings, indicating that the communities oscillate between states which they occupy for varying periods of time. Fig. 3 shows the species contributing to at least $80 \%$ of the differences between clusters at each site based on SIMPER analyses. Variations in the abundance of the barnacles Tetraclita serrata and Chthamalus dentatus account for more than $50 \%$ of the differences between clusters in the lower balanoid zones at Mazeppa (avg. dissimilarity: 40\%) and Dwesa (avg. dissimilarity: $37 \%$ ), while C. dentatus and the periwinkle Nodilittorina africana account for approximately $65 \%$ of the difference between clusters on the lower shore at Mkambati (avg. dissimilarity: $35 \%$ ). The remaining 15 to $30 \%$ of the differences are due to $N$. africana and the barnacle Octomeris angulosus at Mazeppa, and to $N$. africana, $O$. angulosus and

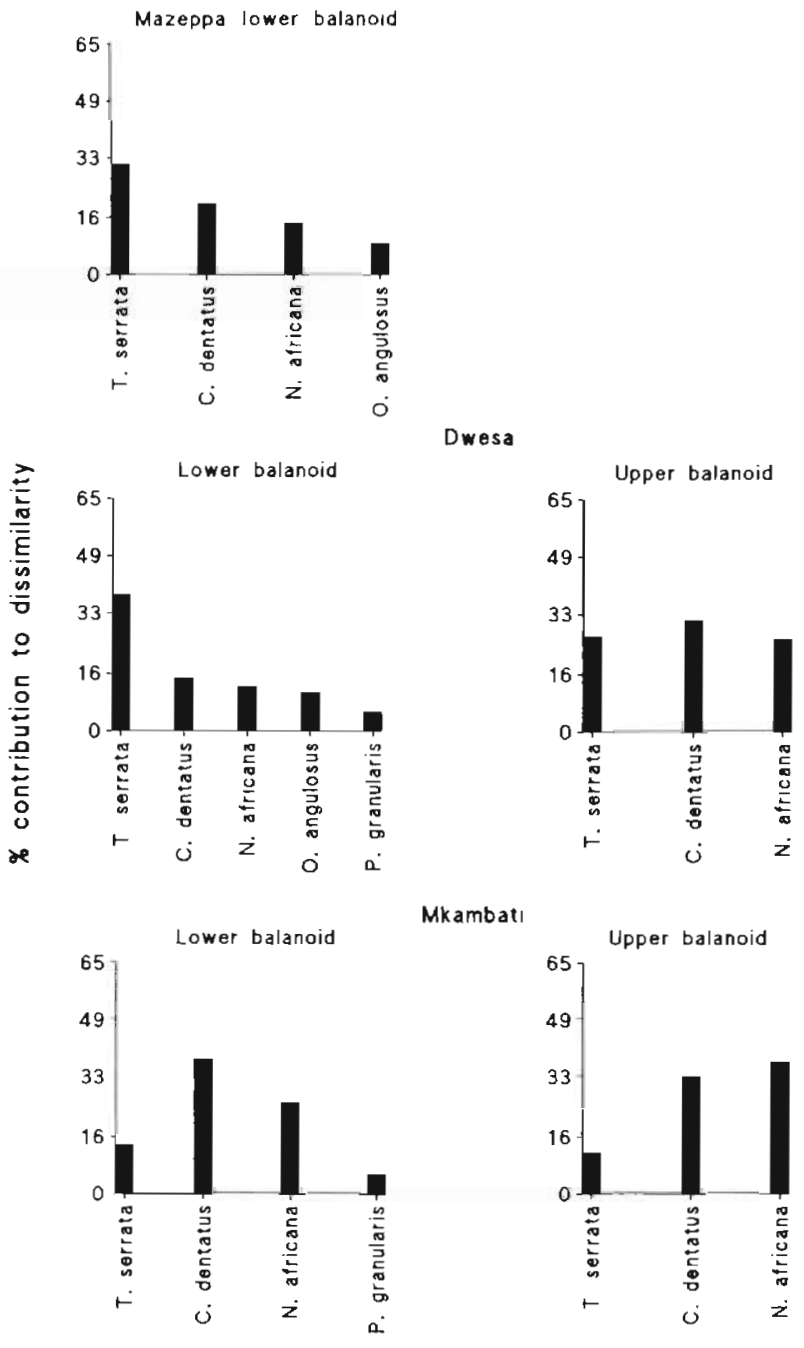

Fig. 3. Species contributing cumulatively to at least $80 \%$ of the mean difference between MDS clusters from undisturbed areas at Mazeppa, Dwesa and Mkambati. T. serrata: Tetraclita serrata; $C$. dentatus: Chthamalus dentatus; $N$. africana: Nodilittorina africana; $O$. angulosus: Octomeris angulosus; $P$. granularis: Patella granularis

the limpet Patella granularis at Dwesa. At Mkambati the remainder is due to variations in the abundance of $T$. serrata and $P$. granularis. On the upper shore at Dwesa (avg. dissimilarity: $35 \%$ ) most of the differences between clusters is due to $T$. serrata, $C$. dentatus and $N$. africana in approximately equal proportions, while at Mkambati (avg. dissimilarity: 36.4\%) C. dentatus and $N$. africana account for most of the difference, with $T$. serrata third.

MDS ordinations for seasonally disturbed communities (see Fig. 2 for an example) indicate that they too occupy discrete states over time. Communities occupied the greatest number of states at Dwesa and the least at Mazeppa. At Mazeppa areas cleared in the lower balanoid zone in summer and autumn rapidly 
converged to a single state which persisted throughout the study. At Mkambati, however, the convergence occurred in areas cleared in winter and spring. No such convergence was evident on the lower shore at Dwesa (avg. dissimilarity: $40.3 \%$ ). SIMPER analyses once again revealed that barnacles accounted for most of the difference between clusters in disturbed areas (Fig. 4). At Mazeppa (avg. dissimilarity: $51 \%)$ Tetraclita serrata accounted for most of the difference, its contribution being greatest in summer and least in spring. Other species of importance at this site were Nodilittorina africana and Octomeris angulosus. While T. serrata was the most important discriminator between clusters on the lower shore at Dwesa, its relative importance depended on the season of initial clearing. For areas cleared in spring it accounted for over $60 \%$ of the difference while in autumn its contribution was only $30 \%$. The next most important species was Chthamalus dentatus, with $N$. africana, $O$. angulosus and Patella granularis making up the remainder. On the lower shore at Mkambati C. dentatus was the major discriminator between clusters in all seasons, with $T$. serrata and $N$. africana accounting for the rest.

The picture was somewhat different for the upper-shore community at Dwesa (avg. dissimilarity: $50.8 \%$ ) where a greater number of species contributed to the first $80 \%$ of differences between clusters. In this case the major discriminators, Tetraclita serrata and Chthamalus dentatus, dominated in areas cleared in spring and winter respectively, while in other seasons they were equally important. The remainder of the differences were due to Nodilittorina africana, Octomeris angulosus (spring and autumn only), the limpets Cellana capensis and Siphonaria concinna and the periwinkle Oxystele tabularis. On the upper shore at Mkambati the picture was simpler with $C$. dentatus accounting for most of the difference between clusters in all seasons and $N$. africana accounting for the rest.

Fig. 5 shows the MDS timelines for undisturbed communities in the upper balanoid zones at Dwesa and Mkambati and for the lower balanoid zones at Mazeppa, Dwesa and Mkambati. The upper shore community at Dwesa occupied a single state, dominated by Tetraclita serrata and Nodilittorina africana, from November 1982 until February 1990, after which it underwent a change, taking about $9 \mathrm{mo}$, before stabilizing at a new state, dominated by Chthamalus dentatus and $N$. africana, which persisted until August 1996. At Mkambati the upper shore community experienced a protracted period of instability between

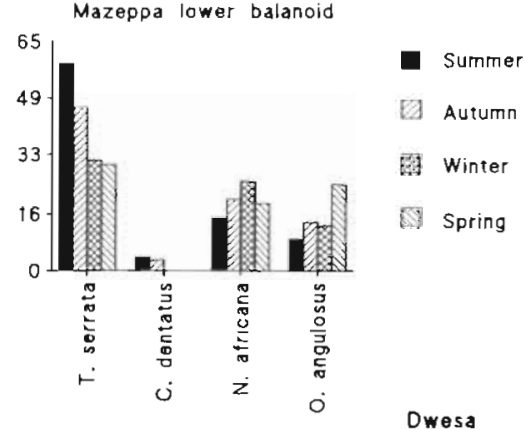

Fig. 4. Species contributing cumulatively to at least $80 \%$ of the mean difference between MDS clusters from seasonally cleared areas at Mazeppa, Dwesa and Mkambati Species names as in Fig. 3
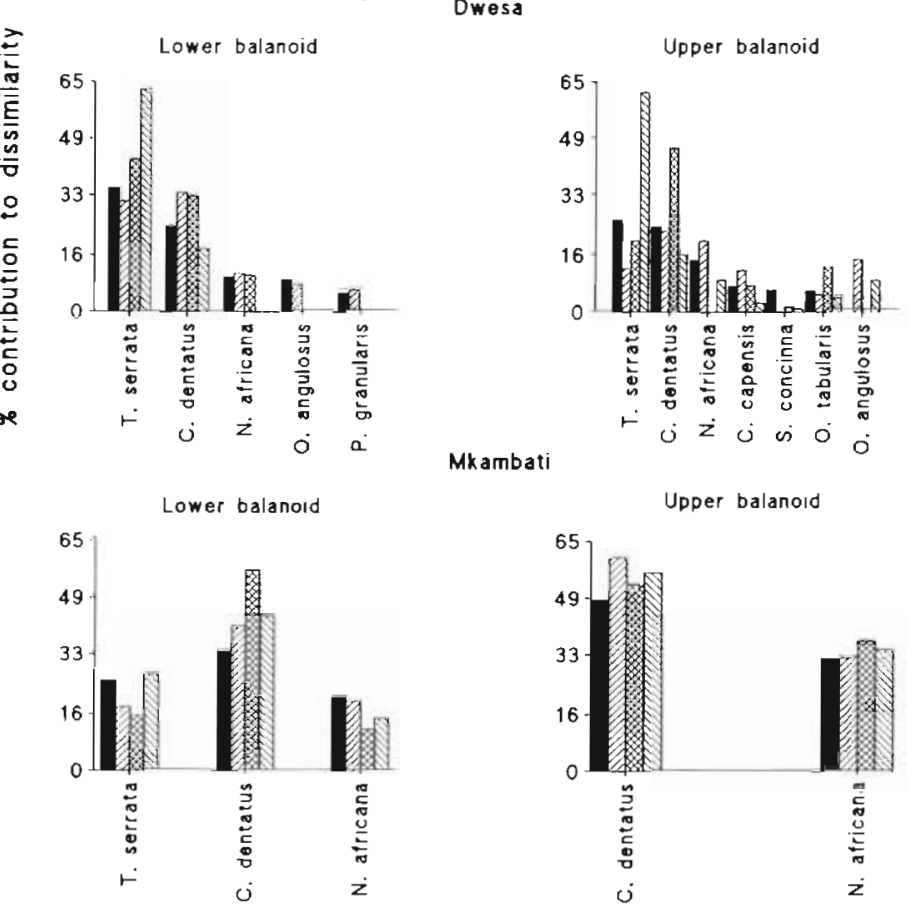

August 1985 and August 1987, when it stabilized in a state dominated by Saccostrea cucullata and C. dentatus, until November 1990 before entering its current state which is characterized by large numbers of $C$. dentatus and $N$. africana. The fact that both sites experienced substantial changes during 1990 accounts for the significant correlation between them (Pearson correlation, $r=0.78 ; \mathrm{p} \leq 0.001$ ).

The timelines also indicate a period of instability in the lower shore communities in the early 1990s. Between 1983 and 1990 the lower shore community at Mazeppa underwent regular oscillations between states, each lasting for about $18 \mathrm{mo}$, and resulting from periodic settlement of large numbers of Tetraclita serrata. After this time the community changed briefly in 1992 but otherwise remained stable until 1996. At Dwesa the lower shore community was stable until 1990 (dominated by $T$. serrata, Chthamalus dentatus and Octomeris angulosus), when it entered a period of severe instability during which it oscillated between 3 different states, reflecting changes in the relative 
abundance of $T$. serrata, over a period of 18 mo before assuming its final state. The lower shore community at Mkambati exhibited high frequency oscillations between 2 states, one dominated by $T$. serrata and the other by C. dentatus, from November 1983 to August 1986, after which it stabilized in a third state in which $C$. dentatus became more abundant for 4.5 $y r$, before flipping back to the original state for $1 \mathrm{yr}$ and then assuming the third state again until August 1996. Correlation analyses revealed significant correlation between the 2 southern sites, Mazeppa and Dwesa $(\mathrm{r}=$ $0.43 ; \mathrm{p} \leq 0.002$ ), but no correlation with the northern site. There was a significant within-site correlation of timelines between the upper and lower shore at Dwesa $(r=0.85 ; \mathrm{p} \leq$ 0.0001 ), but this was not evident at Mkambati.

Timelines for cleared areas on the low-shore at Mazeppa, Dwesa and Mkambati are also shown in Fig. 5. Despite their close proximity only 2 of the timelines correlated with each other, or with the undisturbed areas, at Mazeppa. Areas cleared in summer and autumn converged to a single state, dominated by Tetraclita serrata and Nodilittorina africana, within a year and remained that way until the end of the study. Areas cleared in winter and spring, however, exhibited greater instability and oscillated between 3 states, one of which was characterized by the absence of Chthamalus dentatus, and the others by the relative abundance of $T$, serrata, the winter cleared area returning to the original state by August 1990, and the summer cleared area drifting to the third state over time. These 2 correlated weakly $(r=0.32 ; p \leq 0.02)$ while the spring cleared area correlated more strongly with the undisturbed areas $(\mathrm{r}=0.45 ; \mathrm{p} \leq 0.001)$. The situation was highly variable at Dwesa with only 2 significant correlations, those between summer and autumn $(r=0.76$; $p$ $\leq 0.0001)$ and between summer and winter $(r=0.49 ; p$ $\leq 0.001$ ). In these cases the community oscillated between as many as 4 states, defined mainly by the relative abundance of $T$. serrata and $C$. dentatus, with a general drift away from the initial condition. Areas cleared in spring exhibited no clear pattern with
Fig. 5. Timelines of MDS ordination traces from undisturbed and seasonally cleared areas at Mazeppa, Dwesa and Mkambati. UN: undisturbed; SU: summer; AU: autumn; WI: winter; SP = spring
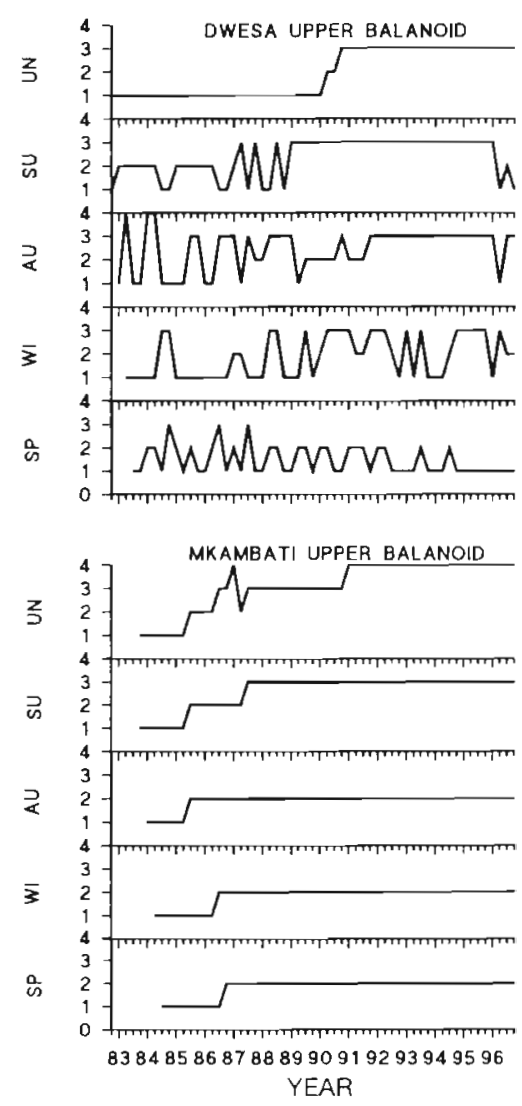

respect to their oscillations. There were no correlations with the undisturbed condition. At Mkambati the only significant correlation occurred between summer and autumn cleared areas $(\mathrm{r}=0.76 ; \mathrm{p} \leq 0.0001)$. Both exhibited variability between 1984 and 1986, becoming stable until 1990, which represented the start of a period of instability which lasted until the end of 1992, after which they entered a stable state until 1996. Areas cleared in winter and spring tended to converge to a single stable state which, apart from a brief period of instability in the latter in the early 1990s, persisted until the end of the study. This state was dominated by C. dentatus. The only significant between-site correla- 
tions were those of areas cleared in summer on the upper shores at Dwesa and Mkambati $(\mathrm{r}=0.45 \mathrm{p} \leq$ $0.001)$.

Irrespective of season, there was considerable instability in cleared areas in the upper balanoid zone at Dwesa. Areas cleared in summer and autumn oscillated frequently between states up to 1989 or 1990 , becoming more stable thereafter, when the community was dominated by Tetraclita serrata. Areas cleared in winter and spring were unstable throughout the study. Apart from the summer cleared areas, which correlated significantly with undisturbed areas ( $r=0.50$ $p \leq 0.0001$ ), there were no significant correlations. The picture was very different on the upper shore at Mkambati, where all cleared areas converged to a single stable state after about $3 \mathrm{yr}$. In this case the community was dominated by Chthamalus dentatus and Nodilittorina africana. Not surprisingly, all treatments correlated significantly with each other and with the undisturbed areas (overall $\mathrm{p} \leq 0.0001$ ). As in the case of the lower shore the only significant betweensite correlation was with areas cleared in summer at Dwesa and Mkambati ( $r=0.31 ; p \leq 0.03$ ). The only significant correlation between tidal levels was for areas cleared in winter at Mkambati $(x=0.62 ; p \leq 0.0001)$.

\section{DISCUSSION}

Although long-term studies of rocky intertidal systems are rare, they have illustrated the complex dynamics which characterize benthic populations in these habitats. Dye (in press) has shown that, on the east coast of South Africa, the nature of temporal fluctuations in the abundance of rocky intertidal populations varies with the temporal and spatial scale of measurement. Dye (in press) showed that at small scales (months, 10 s of metres) populations generally exhibit high frequency fluctuations independently of each other, while at larger scales (years, 10s of kilometres) a significant degree of correlation between different species, and between conspecifics at different sites, emerges. Only at larger spatial scales (100s of kilometres) are these correlations attenuated. This rather complex picture can be simplified through an examination of temporal fluctuations at the community level, by using one or more of the many univariate indices of community structure, such as diversity, or by adopting a multivariate approach in which communities are described graphically through some ordination procedure.

The Shannon-Wiener diversity index embodies information on species richness and evenness (Magurran 1988). Dye (in press) showed that intertidal communities on the east coast of South Africa rarely suffer a loss of species and in general the same suite of species is present over long periods of time. In the present study the richness component is fairly constant and it follows therefore that variations in diversity arise mainly from changes in the relative abundance of species which affects evenness. The regular annual cycles evident in time series from undisturbed areas reflect the annual cycle of recruitment, which occurs mainly in winter (Dye in press). The presence of biennial cycles at some sites may suggest that recruitment varies in intensity with 'good' years being followed by 'poor' years, possibly driven by density-dependent factors. Further analyses of the photographic record should shed light on this

Between 1983 and 1990 the abundance of the dominant barnacle Tetraclita serrata declined at all undisturbed sites (Dye in press). At Mazeppa this species was replaced by another barnacle, Octomeris angulosus, which also declined after 1990. The overall effect was a decline in diversity, followed by an increase. The same thing happened at Dwesa and Mkambati except that $T$. serrata was initially replaced by Chthamalus dentatus, which was associated with an increase in the abundance of periwinkles. An interesting teature is that diversity in many of the undisturbed areas was significantly more variable in the period up to 1990 than thereafter. This, together with the changes in species abundance which occurred around 1990 (Dye in press), may be indicative of some large-scale external factor that had a profound and persistent effect on the structure of these communities. In most cases this has resulted in a community structure which differs considerably from that which existed 14 yr ago.

Since the cleared areas started from a zero base, it is not surprising that time series of diversity differ from those of undisturbed areas and tend to increase with time. Initially this is due to the addition of species, but from about 1990 onwards fluctuations in diversity reflect changes in the abundance of barnacles and periwinkles. Despite the increase over time, disturbed areas generally did not return to their pre-disturbed levels of diversity. Experimental disturbance clearly induced changes in these communities which continue to distinguish them from undisturbed areas. What is remarkable is the persistence of these effects.

The persistent effects of stochastic events and experimental disturbance become even more striking when communities are described in multivariate terms. The fact that communities occupy different states is clear from the MDS ordinations, and SIMPER analysis confirms that most of the difference between these states, whether disturbed or not, arises from variations in the abundance of barnacles and periwinkles. However, only by examining time traces of the ordinations can an impression of the dynamics of these communities be obtained. 
Upper shore communities at Dwesa and Mkambati exhibited remarkable stability during the study. At Dwesa the only change occurred during 1990, when there was a drastic decline in the abundance of Tetraclita serrata and Nodilittorina africana, the latter recovering only when Chthamalus dentatus replaced the other barnacle, leading to a new community state which persisted to the end of the study. At Mkambati the high-shore community experienced 2 periods of instability, both resulting from fluctuations in the relative abundance of $T$. serrata, $N$. africana and $C$. dentatus. In this case $C$. dentatus became abundant between 1987 and 1990, leading to an intermediate state. The abundance of this barnacle decreased after 1990 , but it still remained more abundant than previously (Dye in press).

The regular oscillation of the lower shore community at Mazeppa correlated with fluctuations in the abundance of periwinkles, which exhibited strong biennial cycles (Dye in press). During 1990, however, the abundance of Tetraclita serrata declined by about $80 \%$, although it remained numerically dominant (Dye in press), resulting in a change in state which persisted to the end of the study. The fact that all 3 sites show instability around the same time and that low-shore communities at Dwesa and Mkambati exhibited the same dynamics as on the upper shore indicates that some external factor may be driving these changes. Variations in the supply of planktonic propagules have been noted in a number of studies (Hawkins \& Hartnoll 1982, Kendall et al. 1982, Caffey 1985, Connell 1985. Gaines et al. 1985) and it is known that such variations can profoundly affect the structure of intertidal populations. Variations in larval supply can result from changes in wind and current patterns, and it is known that anomalous oceanographic conditions occurred along the South African coast between 1989 and 1991 (van Ballegooyen et al. 1996). Changes in abundance may also result from variations in post-settlement mortality (Raimondi 1990). It is interesting that the barnacle which replaced $T$. serrata is adapted to mid- to high-shore conditions and may have been favoured during the drought conditions which prevailed during the same period. Again, what is surprising is the persistence of these changes, which, in most cases, exceeds the turnover of the dominant species (Dye 1992, 1993) and raises the possibility that the system may exist in more than one stable state.

Although studies have shown that disturbance can alter community structure, the effects are often shortlived and the system usually returns to something approximating the initial state (Dayton 1971, Sousa 1980, Turner et al. 1995). Few studies have shown alterations in state which exceed the turnover time of the resident populations (Southward 1978). The pre- sent study shows that the long-term effects of disturbance are variable. At some sites communities stabilized fairly quickly while at the other sites they exhibited considerable instability. What is notable once again is the persistence of the instability. While almost all of the undisturbed areas adopted one or more stable configurations, only $40 \%$ of cleared areas did so.

The almost complete absence of correlations between diversity time series, both undisturbed and disturbed, would appear to lend support to the original hypothesis that fluctuations in community structure are driven by largely stochastic processes which are spatially independent. However, inspection of the multivariate timelines suggests that there is indeed a significant degree of correlation in changes in community structure at different scales. This contradiction may arise because the univariate diversity index is not sensitive enough to detect subtle changes in community structure which are more evident in a multivariate analysis. Lasiak \& Field (1995) compared both approaches in a study of low-shore community structure on the same shores as in the present study and found that univariate measures, such as species diversity, were poor discriminators of differences in community structure between shores subjected to shellfish gathering and those protected within reserves. The multivariate approach, as used in the present paper, produces a much better representation of spatial and temporal differences in community structure.

Although long-term stability is probably illusory (Connell \& Sousa 1983), this study shows that rocky intertidal communities can exist in a number of seemingly stable states (sensu Sutherland 1990), which may persist for periods ranging from 7 to 13 yr and which greatly exceed the turnover time of the resident populations. Experimental disturbance, as well as episodic factors, acting over large spatial scales, can induce persistent alterations in state, which are defined by the relative proportions of abundant species, particularly barnacles and periwinkels.

Acknowledgements. The author acknowledges the financial support of the University of Transkei and the Foundation for Research Development. The following assisted with field work at various times: Dr T A. Lasiak, Dr W. Emmerson, Dr J. E. Granger and Mr T. Robey. The former Transkei Division of Nature Conservation and Eastern Cape Nature Conservation are thanked for providing access to coastal nature reserves

\section{LITERATURE CITED}

Barnes H (1956) Balanus balanoides (L.) in the Firth of Clyde: the development and annual variation of the larval population, and the causative factors. J Anim Ecol 25:72-84

Barry JP, Baxter CH, Sagarin RD, Gilman SE (1995) Climate- 
related, long-term faunal changes in a California rocky intertidal community. Science 267:672-675

Butler AJ, Chesson PL (1990) Ecology of sessile animals on subtidal hard substrata: the need to measure variation. Aust J Ecol 15:521-531

Caffey HM (1985) Spatial and temporal variation in settlement and recruitment of intertidal barnacles. Ecol Monogr $55: 313-332$

Chatfield C (1989) The analysis of time series an introduction. Chapman and Hall, London

Clarke KR (1993) Non-parametric multivariate analyses of changes in community structure. Aust J Ecol 18:117-143

Connell JH (1985) The consequences of variation in initial settlement vs post-settlement mortality in rocky intertudal communities. J Exp Mar Biol Ecol 93:11-45

Connell JH, Sousa WP (1983) On the evidence needed to judge ecological stability or persistence. Am Nat 121 $789-824$

Dayton PK (1971) Competition, disturbance and community organization: the provision and subsequent utilization of space in a rocky intertidal community Ecol Monogr 54: $99-118$

Diggle PJ (1990) Time series a biostatistıcal introduction. Oxford Science Publications, Oxford

Dungan ML (1986) Three-way interactions: barnacles, limpets and algae in a Sonoran Desert rocky intertidal zone. Am Nat 127-297-316

Dye AH (1988) Rocky shore surveillance on the Transkei coast, southern Africa: temporal and spatial variability in the balanoid zone at Dwesa. S Afr J Mar Sci 7:87-99

Dye AH (1990) Episodic recruitment of the rock oyster Saccostrea cucullata (Born, 1778) on the Transkei coast. S Afr J Zool 25:185-187

Dye AH (1992) Recruitment dynamics and growth of the barnacle Tetraclita serrata on the east coast of southern Africa. Estuar Coast Shelf Sci 35:167-177

Dye AH (1993) Aspects of the population dynamics of Chthamalus dentatus (Crustacea: Cirripedia) on the Transkei coast of southern Africa. S Afr J Mar Sci 13:25-32

Dye AH (1995) The effects of excluding limpets from the lower balanoid zone of rocky shores in Transkei, South Africa. S Afr J Mar Sci 15:9-15

Dye AH (in press) Dynamics of rocky intertidal communities: analyses of long time series from South African shores. Estuar Coast Shelf Sci

Dye AH, White DRA (1991) Intertidal microalgal production and molluscan herbivory in relation to season and elevation on two rocky shores on the east coast of southern Africa. S Afr J Mar Sci 11:483-489

Ellner S, Turchin P (1995) Chaos in a noisy world: new methods and evidence from time-series analysis. Am Nat 145: 343-375

Fairweather PG (1988) Consequences of supply-side ecology: manipulating the recruitment of intertidal barnacles affects the intensity of predation upon them. Biol Bull (Woods Hole) 175:349-354

Foster MS, Schiel DR (1993) Zonation, El Niño disturbance and the dynamics of subtidal. vegetation along a $30 \mathrm{~m}$ depth gradient in two giant kelp forests. In: Battershill CN, Schiel DR. Jones GP, Creese RG, MacDiarmid AB (eds) Proc 2nd Int Temperate Reefs Symp, Auckland, 1992

Francis MP, Evans J (1993) Immigration of subtropical and tropical animals into northeastern New Zealand. In: Battershill CN, Schiel DR, Jones GP, Creese RG, MacDiarmid $A B$ (eds) Proc 2nd Int Temperate Reefs Symp, Auckland, 1992

Frid CL, Buchanan JB, Garwood PR (1996) Variahility and stability in benthos: twenty-two years of monitoring off Northumberland. J Mar Sci 53:978-980

Gaines SD, Brown S, Roughgarden J (1985) Spatial variation in larval concentration as a cause of spatial variation in settlement for the barnacle, Balanus glandula. Oecologia 67:267-272

Garrity SD, Levings SC (1981) A predator-prey interaction between two physically and biologically constrained tropical rocky shore gastropods: direct, indirect and community effects. Ecol Monogr 51:267-286

Hawkins SJ, Hartnol]. RG (1983) Changes in a rocky shore community: an evaluation of monitoring. Mar Environ Res 9:131-181

Hawkins SJ, Hartnoll SG (1982) Settlement patterns of Semibalanus balanoides in the Isle of Man. J Exp Mar Biol Eco] 62:271-283

Judge ML, Quinn JF, Wolin CL (1988) Variability in recruitment of Balanus glandula (Darwin, 1854) along the central California coast. J Exp Mar Biol Ecol 119:235-251

Kendall MA, Bowman RS, Williamson P (1982) Settlement patterns, density and stability in the barnacle Balanus balanoides. Neth J Sea Res 16:119-126

Kendall MA, Bowman RS, Williamson P, Lewis J (1985) Annual variation in recruitment of Semibalanus balanoides on the North Yorkshire coast 1969-1981. J Mar Biol Assoc UK 65:1009-1030

Lasiak TA, Field JG (1995) Community-level attributes of exploited and non-exploited rocky infratidal macrofaunal assemblages in Transkei. $J$ Exp Mar Biol Ecol 185:33-53

Lewis JR (1976) Long-term ecological surveillance: practical realities in the rocky littoral. Oceanogr Mar Biol Annu Rev $14: 371-390$

Lively CM, Raimondi PT, Delph LF (1993) Intertidal community structure: space-time interactions in the northern Gulf of California. Ecology 74:162-173

Luckins PA (1976) Settlement and succession on rocky shores at Auckland, North Island, New Zealand. NZ Oceanogr Inst Mem. 70:1-64

Magurran AE (1988) Ecological diversity and its measurement. Croom Helm, London

Menge BA, Lubchenco J, Ashkenas LR, Ramsey F (1986) Experimental separation of the effects of consumers on sessile prey in the low zone of a rocky shore in the Bay of Panama: direct and indirect consequences of food web complexity. J Exp Mar Biol Ecol 100:225-269

Paine RT (1986) Benthic community-water column coupling during the 1982-1983 El Niño. Are community changes at high latitudes attributable to cause or coincidence? Limnol Oceanogr 31:351-360

Petraitis PS (1990) Direct and indirect effects of predation, herbivory and surface rugosity on mussel recruitment. Oecologia 83:405-413

Pumm SL, Redfearn A (1.988) The variability of populdtion densities. Nature 334:613-614

Raimondi. PT (1990) Patterns, mechanisms, consequences of variability in settlement and recruitment of an intertidal barnacle. Ecol Monogr 60:283-309

Sousa WP (1980) The responses of a community to disturbance: the importance of successional age and species' life histories. Oecologia 45:72-81

Southward AJ (1967) Recent changes in abundance of intertidal barnacles in south-west England, a possible effect of climatic deterioration. J Mar Biol Assoc UK 47:81-95

Southward AJ (1978) Cyclic fluctuations in population density during eleven years recolonization of rocky shores in west Cornwall following the 'Torrey Canyon' oil-spill in 1.967 In: Naylor E, Hartnoll RG (eds) Cyclic phenomena in 
marine plants and animals. Proc 13th Eur Mar Biol Symp, Isle of Man. Pergamon Press, Oxford, p 85-92

Southward A.J (1991) Forty years of change in species composition and population density of barnacles on a rocky shore near Plymouth. J Mar Biol Assoc UK 71:495-513

Southward AJ (1995) The importance of long time series in understanding the variability of natural systems. Helgol Meeresunters 49:329-333

Southward AJ, Hawkins SJ, Burrows MT (1995) Seventy years' observations of changes in distribution and abundance of zooplankton and intertidal organisms in the western English Channel in relation to rising sea temperature. J Therm Biol 20:127-155

Steele JH (1985) A comparison of terrestrial and marine ecological systems. Nature 313:355-358

Sutherland JP (1990) Perturbations, resistance, and alternative views of the existence of multiple stable points in nature. Am Nat 136:270-275

Turchin P, Taylor AD (1992) Complex dynamics in ecological time series. Ecology 73:289-305

Turner SJ, Thrush RD, Hewitt JE, Cummings VJ, Maskery M

Editorial responsibility: Otto Kinne (Editor),

Oldendorf/Luhe, Germany
(1995) Are soft-sediment communities stable? An example from a windy harbour. Mar Ecol Prog Ser 120:219-230

Underwood AJ (1984) Vertical and seasonal patterns in competition for microalgae between intertidal gastropods. Oecologia 64:211-222

van Ballegooyen RC, Brundrit GB, Lutjeharms JRE (1996) Major episodic perturbations of the Agulhas Current and their impact on the shelf and nearshore environment. 9th Natl Oceanogr Symp, Cape Town, November 1996

Warwick RM (1986) A new method for detecting pollution effects on marine macrobenthic communities. Mar Biol 92 $557-562$

Warwick RM, Clarke KR (1991) A comparison of some methods for analysing changes in benthic community structure. J Mar Biol Assoc UK 71:225-244

Warwick RM, Clarke KR (1993) Comparing the severity of disturbance: a meta-analysis of marine macrobenthic community data. Mar Ecol Prog Ser 92:221-231

Warwick RM, Clarke KR (1995) New 'biodiversity' measures reveal a decrease in taxonomic distinctness with increasing stress. Mar Ecol Prog Ser 129:301-305

Submitted: October 22, 1997; Accepted: December 1, 1997 Proofs received from author(s): March 19, 1998 